\title{
Design basis development for centrifugal turbo machines with a coaxial impellers location for mining-and-metallurgical industry conditions
}

\author{
S.V. Podbolotov ${ }^{1, *}$, A.D. Kolga ${ }^{1}$, B.M. Gabbasov ${ }^{1}$, and A.I. Kurochkin ${ }^{1}$ \\ ${ }^{1}$ Nosov Magnitogorsk State Technical University, Magnitogorsk, Russia
}

\begin{abstract}
The article considers the main ways to improve the modern designs of centrifugal turbo machines. The existing methods of their design are analyzed. One of the development options is considered which consists in using the coaxial impellers location in centrifugal turbo machines. A technique for designing a coaxially mounted impeller is presented.
\end{abstract}

\section{Introduction}

The constant growth of world production, regardless of the general economic situation, leads to an increase in the use of centrifugal turbo machines in almost all sectors of human activity. In highly developed countries, centrifugal turbo machines are an important export product; their role in the domestic economy is also high.

Centrifugal turbo machines make up a significant part of the pump, fan and compressor units used in the mining industry. The wide area of use is often dictated by their high reliability, simplicity of design and low cost.

The improvement of modern designs of centrifugal turbo machines follows the path of further increasing specific power, while at the same time tightening requirements for energy efficiency, reliability and resource.

Along with the search for ways to improve the design of these machines, the methods of calculating their gas-dynamic characteristics do not stop improving, new mathematical models of calculation are developed that more fully reflect the features of the work process.

The basis of most existing design methods is the principle of turbo machines similarity. The parameters of the developed turbo machines are calculated according to the theory of similarity using the parameters of the produced stages [1-3]. With geometric similarity and equality of similarity criteria, the dimensionless gas-dynamic characteristics of the tested turbo machines exactly correspond to the characteristics of turbo machines with other sizes and working in other conditions.

When designing completely new constructions that are fundamentally different from others, it is necessary to create expensive full-scale models, or to develop mathematical models that include certain assumptions that equate the internal processes of the designed turbo machines with the previously studied types.

\footnotetext{
${ }^{*}$ Corresponding author: podbolotov_sergey@mail.ru
} 


\section{Methodology}

A centrifugal turbomachine with a coaxial impellers location $[4,5]$ is a new design; there is currently no experimental experience with full-scale models with this design. Therefore, the construction design of a centrifugal turbomachine will require a detailed analysis of existing mathematical design techniques, with a view to the possibility of their further use. Conducting mathematical modeling of the processes of a fluid flow in a centrifugal stage will help to evaluate the influence of applied structural solutions on the parameters of the stage and to pay attention to problem areas.

The analysis is performed by considering the existing design methodology. Using this technique implies the presence of the initial required parameters (flow rate, pressure) under which the design of the turbomachine impeller is already calculated.

The design process is divided into three levels:

- Selection of basic parameters;

- Design of the meridian section;

- Design of the blade system.

The flowchart of the calculation algorithm for the flow part of the centrifugal supercharger for mining and metallurgical industry is presented in Figure 1.

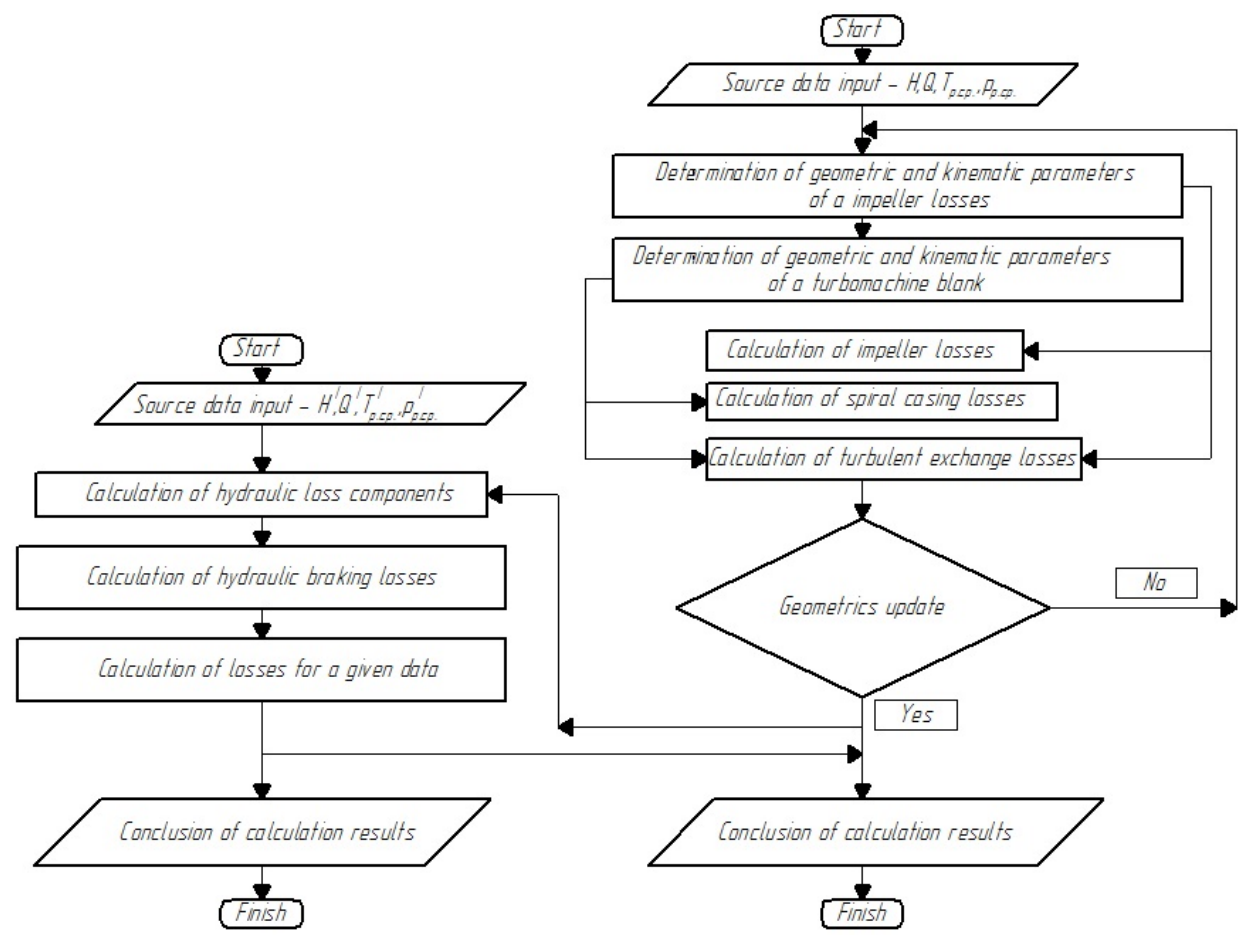

Fig. 1. Block diagram of the calculation algorithm of a centrifugal supercharger

At the first hierarchical level, they are optimized: D2, D0 / D2 (or $\alpha$ ), b2 / D2 (or Vm1 / $\mathrm{Vm} 2$ ), $\beta$ л2, (or W1 / W2), z, $\delta \_1, \delta \_2$. The angle of the blade at the entrance $\beta 11$ or the angle of attack $\Delta \beta 1$ at the upper $\left(\mathrm{I}_{- \text {th }}\right)$ hierarchical level is specified in the first approximation, then it is refined (and can vary) when designing the blade system at the third hierarchical level.

At the second hierarchical level, the meridian section is optimized. The meridian section of the I can be designed in one of two ways: 
- based on the solution of the inverse hydrodynamic problem, when, according to a given law, a change occurs;

- the meridian section is projected according to the geometric model, and then the direct hydrodynamic problem is solved and the quality of the designed profile is evaluated;

At the third hierarchical level, a blade system is designed and optimized. Designing is carried out in two stages: first, the position of the input and an output edge is determined, and then on separate surfaces of the current grid profiles are designed, which begin to form with the choice of angle of attack [3].

It is relevant to consider each level in more detail. We start by calculating the basic geometric dimensions, and then gradually proceed to the calculation of the meridian section.

The design of the impeller largely depends on the speed coefficient ns, the value of which can be determined by the following dependence [6]:

$$
\mathrm{n}_{\mathrm{s}}=3,65 \cdot \mathrm{n} \cdot \frac{\sqrt{\mathrm{Q}}}{\mathrm{H}^{3 / 4}}
$$

Volumetric efficiency $\eta \_0$ is calculated by the formula:

$$
\eta_{\mathrm{o}}=\frac{1}{1+\mathrm{a} \cdot \mathrm{n}_{\mathrm{s}}{ }^{-2 / 3}}
$$

where $\mathrm{a}$ is the coefficient depends on the ratio between the diameters of the input and output and is about 0.68 .

The reduced diameter D1 $п$ at the inlet is found by the formula:

$$
\mathrm{D}_{1 \text { п }}=(4 \div 4,5) \cdot 10^{3} \cdot \sqrt[3]{\frac{\mathrm{Q}}{\mathrm{n}^{\prime}}}
$$

Based on the obtained diameter, the hydraulic efficiency $\eta_{\Gamma}$ is determined:

$$
\eta_{\Gamma}=1-\frac{0,42}{\left(\operatorname{lgD}_{1 \Pi p}-0,172\right)^{2}}
$$

For modern centrifugal turbo machines, mechanical efficiency reaches $\eta_{\mathrm{M}}=0,92 \div$ $0,96[7,8]$ :

The full efficiency [5] $\eta$ of the turbomachine is calculated by the formula:

$$
\eta=\eta_{\mathrm{o}} \eta_{\Gamma} \eta_{\mathrm{M}}
$$

Knowing the full efficiency is determined by the pump power and torque on the shaft:

$$
\begin{aligned}
& \mathrm{N}=\frac{\rho \mathrm{QHg}}{1000 \eta} \\
& \mathrm{N}_{\max } \approx 1,1 \mathrm{~N}
\end{aligned}
$$

Torque is determined by the formula:

$$
M=97500 \frac{N}{n}
$$

Having determined the pump power and torque on its shaft, the diameter of the pump shaft is calculated.

The pump shaft works mainly for torsional moment M, but is partially loaded with transverse forces of its own weight and centrifugal forces due to the unbalance of the rotor. 
Therefore, the permissible torsion stress $\sigma \mathrm{cr}$ is taken lower: $\sigma \mathrm{cr}=120-200 \mathrm{kgf} / \mathrm{cm} 2(\sigma \mathrm{cr}$ $=150 \mathrm{kgf} / \mathrm{cm} 2$ ).

$$
\begin{aligned}
\mathrm{d}_{0} & =\sqrt[3]{\frac{\mathrm{M}}{0,2 \sigma_{\mathrm{\kappa p}}}} \\
\mathrm{d}_{\mathrm{BT}} & =1,25 \mathrm{~d}_{0}
\end{aligned}
$$

The estimated wheel feed $Q_{1}^{\prime}$ is greater than the feed $Q_{1}$ by the volume loss. Taking the preliminary value of the volumetric efficiency $\eta_{\text {об }}$ as the calculated flow:

$$
\mathrm{Q}^{\prime}=\frac{\mathrm{Q}}{\eta_{\mathrm{o \sigma}}}
$$

For preliminary selection of $\operatorname{speed}_{0}$, the formula is used:

$$
\mathrm{v}_{0}=\alpha_{0} \sqrt[3]{\mathrm{Q}_{1} \mathrm{n}^{2}}
$$

Impeller Diameter:

$$
\mathrm{D}_{0}=\sqrt{\frac{4 \mathrm{Q}_{1}}{\pi \mathrm{v}_{0}}}
$$

Finally, the speed of entry into the impeller is calculated by the formula:

$$
\mathrm{V}_{0}=\frac{4 \mathrm{Q}_{1}}{\pi\left(\mathrm{D}_{0}^{2}-\mathrm{d}_{\mathrm{BT}}^{2}\right)}
$$

Next is the radius of the midpoint of the blade:

$$
\begin{aligned}
& r_{1}=0,8 \frac{D_{0}}{2} \\
& r_{1}=0,8 \frac{D_{0}}{2}
\end{aligned}
$$

Conditionally accepted:

$$
\mathrm{v}_{\mathrm{m} 1}^{\prime}=\mathrm{v}_{0}
$$

The channel width in the meridian section is determined:

$$
\mathrm{b}_{1}=\frac{\mathrm{Q}}{2 \pi \cdot \mathrm{r}_{1} \cdot \mathrm{v}_{\mathrm{m} 1}^{\prime}}
$$

Preliminarily, the value of the coefficient of constraint of the cross-section K1 (K_1 = $1.1 \div 1.15$ ) is selected, the meridian component of the velocity when entering the blade is found:

$$
\mathrm{v}_{\mathrm{m} 1}=\mathrm{K}_{1} \cdot \mathrm{v}_{\mathrm{m} 1}^{\prime}
$$

Translational velocity

$$
\mathrm{u}_{1}=\omega \cdot \mathrm{r}_{1}
$$

In order to ensure an unstressed flow on the wheel blades, the input angle of the blade $\beta 1$ is chosen equal to $\beta 1.0$, and: 


$$
\begin{aligned}
& \operatorname{tg} \beta_{1.0}=\frac{v_{\mathrm{m} 1}}{u_{1}} \\
& \beta_{1}=\beta_{1.0}+\delta
\end{aligned}
$$

The theoretical pressure is found:

$$
\mathrm{H}_{\mathrm{t}}=\frac{\mathrm{H}}{\eta}
$$

Assuming that the coefficient of the circumferential component of the absolute speed when the flow leaves the wheel is equal to: $\overline{\mathrm{v}}_{\mathrm{u} 2} \approx 0,5$ the approximate translational velocity is found:

$$
\mathrm{u}_{2}=\sqrt{\frac{\mathrm{gH}_{\mathrm{t}}}{\mathrm{v}_{\mathrm{u} 2}}}
$$

Calculation of the output (outer) radius $r 2$ of the wheel:

$$
r_{2}=\frac{u_{2}}{\omega}
$$

Accepted:

$$
\vartheta_{m 2}^{\prime}=0,8 \cdot \vartheta^{\prime}{ }_{m 1}
$$

The value of the coefficient of constraint section $\mathrm{K}$ is within $(1,1-1,15)$.

$$
\sin \beta_{2}=\sin \beta_{1} \cdot \frac{\mathrm{w}_{1}}{\mathrm{w}_{2}} \cdot \frac{\mathrm{K}_{2}}{\mathrm{~K}_{1}} \cdot \frac{\mathrm{v}_{\mathrm{m} 2}^{\prime}}{\mathrm{v}_{\mathrm{m} 1}^{\prime}}
$$

The optimal number of blades for a centrifugal wheel is determined by the expression:

$$
\mathrm{z}=6,5 \frac{\mathrm{r}_{2}+\mathrm{r}_{1}}{\mathrm{r}_{2}-\mathrm{r}_{1}} \sin \frac{\beta_{1}+\beta_{2}}{2}
$$

Having determined the basic geometric parameters, the meridian section of the impeller blade is projected, shown in Figure 2.

The thickness of the blade $\delta$ is chosen either uniform or thinner at the ends. With a variable thickness, its value in the middle part is recommended to be coordinated with the thickness of the wheel disc, chosen for reasons of production technology and strength. In large turbo machines with wide channels, the blade thickness should be checked for bending strength by centrifugal forces [9].

In wheels with an almost radial direction of the midline of the meridian section of the channel, the difference in the length of the midline element ds from the increment of radius $\mathrm{dr}$ is neglected. 


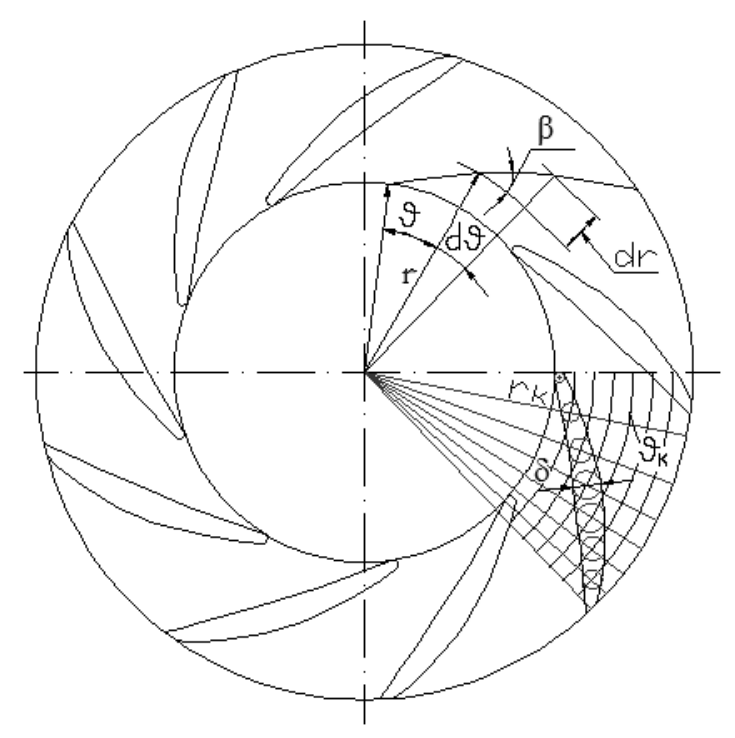

Fig. 2. Construction of a cylindrical blade at the points

The differential equation of the contour midline of the blade has the following form [7]:

$$
\operatorname{tg} \beta=\frac{d r}{r \cdot d v}
$$

It follows:

$$
\mathrm{dv}=\frac{\mathrm{dr}}{\mathrm{r} \cdot \operatorname{tg} \beta}
$$

The angle $\beta$ is a function of $r$, therefore:

$$
\mathrm{v}_{\mathrm{k}}=\int_{\mathrm{r}}^{\mathrm{dr}} \frac{\mathrm{dr}}{\mathrm{r} \cdot \operatorname{tg} \beta}
$$

Due to the fact that the values of $\beta$ and $\delta$ are functions of $r$ and are set in the form of a table, integration is carried out in numerical form.

Denoting the integrand $\frac{\mathrm{dr}}{\mathrm{r} \cdot \operatorname{tg} \beta}=\mathrm{B}(\mathrm{r})$

Find the increment of the central angle:

$$
\Delta v=\frac{B_{i}+B_{i+1}}{2} \cdot \Delta r_{i}
$$

Where $\Delta \mathrm{r}_{\mathrm{i}}, \mathrm{m}$ is the increment of the radius, $\mathrm{Bi}$ and $\mathrm{Bi}+1$ are the values of the integrand at the beginning and at the end of the section under consideration.

$$
\mathrm{v}_{\mathrm{k}}=\sum_{\mathrm{i}-1}^{\mathrm{i}-\mathrm{k}} \frac{B_{\mathrm{i}}+\mathrm{B}_{\mathrm{i}+1}}{2} \cdot \Delta \mathrm{r}_{\mathrm{i}}
$$

Having received $\mathrm{v}$ as a function $\mathrm{r}$, the corresponding points in the plan are applied and the midline of the blade is plotted along the points. Putting at each point of the midline the thickness of the blade $\delta$, one constructs the contour of the blade as compound [10]. 


\section{Conclusion}

The presented design technique allows setting the basic geometric dimensions of the impeller, depending on the required output parameters. Correction of the obtained values can be made based on optimization methods.

\section{References}

1. A. K. Mikhailov, V. V. Malyushenko, Design and calculation of centrifugal high pressure pumps ("Engineering", Moscow, 1971)

2. I.E. Lobanov, Bulletin of Nosov Magnitogorsk State Technical University. 1 (2016)

3. V.N. Makarov, S.A. Gorbunov, T.A. Kornilova, Mountain Journal. 6 (2013)

4. Yu.B. Galerkin, A.F. Rekstin, K.V. Soldatova et al., Compressor technology and pneumatics. 7 (2015)

5. S.G. Chernyy, D.V. Chirkov, V.N. Lapin et al. Numerical modeling of flows in turbo machines (Nauka, Novosibirsk, 2006)

6. S.V. Podbolotov, A.D. Kolga, Vestnik of NMSTU. 4 (2017)

7. A.A. Zharkovsky, Mathematical modeling of work processes in centrifugal pumps of low and medium speed for solving computer-aided design problems (2003)

8. V.M. Cherkassky, Pumps, fans, compressors ("Energy", Moscow, 1977)

9. S.V. Podbolotov, A.D. Kolga, Extraction, processing and use of natural stone. (2016)

10. S. Podbolotov, A. Kolga, N. Dyorina, Matec web of conferences, 224 (2018) 